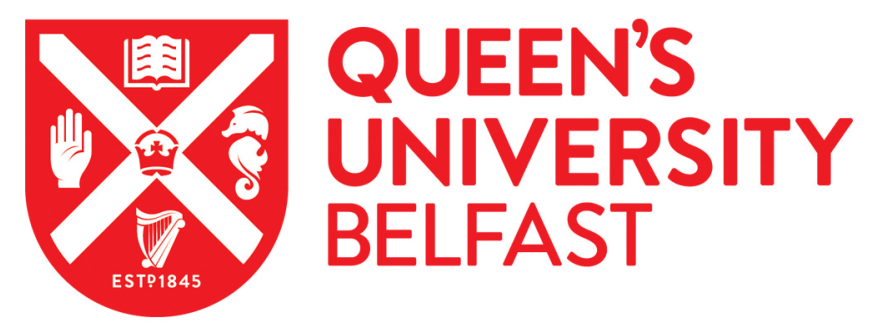

\title{
Properties of Super-Hydrophobic Copper and Stainless Steel Meshes: Applications in Controllable Water Permeation and Organic Solvents/Water Separation
}

Sang, Y. C., Albadarin, A. B., Al-Muhtaseb, A. H., Mangwandi, C., McCracken, J. N., Bell, S. E. J., \& Walker, G. M. (2015). Properties of Super-Hydrophobic Copper and Stainless Steel Meshes: Applications in Controllable Water Permeation and Organic Solvents/Water Separation. Applied Surface Science, 107-114.

https://doi.org/10.1016/j.apsusc.2015.02.034

Published in:

Applied Surface Science

Document Version:

Peer reviewed version

Queen's University Belfast - Research Portal:

Link to publication record in Queen's University Belfast Research Portal

\section{Publisher rights \\ Copyright 2015 Elsevier}

This is the author's version of a work that was accepted for publication in Applied Surface Science. Changes resulting from the publishing process, such as peer review, editing, corrections, structural formatting, and other quality control mechanisms may not be reflected in this document. Changes may have been made to this work since it was submitted for publication. A definitive version was subsequently published in Applied Surface Science, vol 335, 30 April 2015, doi:10.1016/j.apsusc.2015.02.034

\section{General rights}

Copyright for the publications made accessible via the Queen's University Belfast Research Portal is retained by the author(s) and / or other copyright owners and it is a condition of accessing these publications that users recognise and abide by the legal requirements associated with these rights.

\section{Take down policy}

The Research Portal is Queen's institutional repository that provides access to Queen's research output. Every effort has been made to ensure that content in the Research Portal does not infringe any person's rights, or applicable UK laws. If you discover content in the Research Portal that you believe breaches copyright or violates any law, please contact openaccess@qub.ac.uk. 
1 Properties of Super-Hydrophobic Copper and Stainless Steel Mesh and Their

2 Applications in Controllable Water Permeation and Organic Solvents/Water Separation

3

4

21 *Corresponding Author: Dr Ahmad B. Albadarin

22 Email: Ahmad.B.Albadarin@ul.ie

23 Department of Chemical and Environmental Sciences, University of Limerick.

24 Tel: +44 746080 5982; fax: +44 2890976524 .

\author{
Yu Chen Sang ${ }^{1}$, Ahmad B. Albadarin ${ }^{1,2 *}$, Ala'a H. Al-Muhtaseb ${ }^{3}$, Chirangano \\ Mangwandi ${ }^{1}$, John N. McCracken ${ }^{1}$, Steven E.J. Bell ${ }^{1}$, Gavin M. Walker ${ }^{1,2}$
}

${ }^{1}$ School of Chemistry and Chemical Engineering, Queen's University Belfast, Belfast BT9 5AG, Northern Ireland, UK

${ }^{2}$ Department of Chemical and Environmental Sciences, Materials and Surface Science Institute, Synthesis \& Solid State Pharmaceuticals Center (SSPC), University of Limerick, Ireland

${ }^{3}$ Petroleum and Chemical Engineering Department, Faculty of Engineering, Sultan Qaboos University, Muscat-Oman. 


\section{ABSTRACT}

27 The wettability and hydrophobicity of super-hydrophobic ( $\mathrm{SH})$ meshes is greatly influenced by their topographic structures, chemical composition and coating process. In this study, the properties of copper and stainless steel meshes, coated with super-hydrophobic electrolessly

30 deposited silver were investigated. A new method to test the pressure resistance of superhydrophobic mesh was applied to avoid any deformation of mesh. Results showed that SH copper mesh and SH stainless steel meshes with the same pore size have almost the same contact angle and the same hydrophobicity. SH copper mesh with a pore size of $122 \mu \mathrm{m}$ can resist water pressure of $4900 \mathrm{~Pa}$ and a decrease of pore size of mesh can increase the pressure resistance of $\mathrm{SH}$ copper mesh. The $\mathrm{SH}$ copper mesh modified with $0.1 \mathrm{M} \mathrm{HS}\left(\mathrm{CH}_{2}\right){ }_{10} \mathrm{COOH}$ solution in ethanol has a controllable water permeation property by simply adjusting the $\mathrm{pH}$ of water solution. SH copper mesh shows super-oleophilicity with organic solvents and so with a water contact angle of $0^{\circ}$ and it can be an effective tool for organic solvents/water separation. The separation efficiency of SH copper mesh for separating mixtures of organic solvent and water can be as high as $99.8 \%$.

Keywords: Super-hydrophobic copper mesh; Contact angle; Morphology; Pressure resistance; pH-controllable water permeation; Organic solvents/water separation. 


\section{INTRODUCTION}

The self-cleaning ability of natural super-hydrophobic materials such as lotus leaves and butterfly wings have been simulated by artificial super-hydrophobic surfaces with many potential applications [1]. These surfaces have high water contact angle $\left(\theta\right.$ is higher than $\left.150^{\circ}\right)$, low contact angle (CA) hysteresis $[2,3]$ and are produced by combinations of lowering the surface free energy and enhancing the surface roughness [1,2]. Moreover, a super-hydrophobic (SH) mesh has unique characteristics: porous surface, mesh-like geometry, great gas permeation performance, high pressure resistance and high striking loading capacity [4-6]. With the development of offshore oil production and maritime traffic, oil-water separation has become a global challenge due to the frequent industrial oily wastewater and oil spill accidents [7-9]. Current studies have reported the excellent performance of SH meshes in the area of controllable water permeation, oil/water separation and water/organic solvents separation. Cao and co-workers [10] developed an oil/water separation mesh with high separation efficiency and intrusion pressure of water. Cao et al have demonstrated that meshes with both superhydrophobic and oleophobic properties, with a water contact angle higher than $150^{\circ}$ and oil contact angle around $140^{\circ}$, can be used to separate oil from water with separation efficiencies reaching 99.3\% [10]. Also, La and co-workers have reported a super-hydrophobic and superoleophilic copper meshes prepared via a simple electrochemical route that were stable over a wide $\mathrm{pH}$ range of 2 to 14 and over long periods of time. Results exhibited a potential use of the hybrid copper mesh as a filtering layer for oil and water separation [11]. However, there are some problems which seriously hinder the application of superhydrophobic materials for example poor chemical and mechanical stability, low flexibility of metal meshes, use of complicated procedures and expensive materials [12]. The wettability and hydrophobicity of SH mesh is greatly influenced by their topographic structures [13] and chemical composition 
74 Therefore, the aim of this work was to study the properties of copper mesh and stainless steel mesh coated with super-hydrophobic material. Properties such as contact angle, surface topographic structure, $\mathrm{pH}$-controllable permeation property and organic solvents/water separation capability were examined. A new method to test the pressure resistance of superhydrophobic mesh was applied to avoid any deformation of mesh. The connection between contact angle and mesh size was also experimentally and mathematically analyzed.

\section{MATERIALS AND METHODS}

\subsection{Materials}

Copper meshes (\#50-\#120) and stainless steel meshes (\#50-\#250) were purchased from The Mesh Company Ltd, UK. Phenolphthalein powders, analytical grades of $\mathrm{NaOH}$ and $\mathrm{HCl}$, sodium chloride $(\mathrm{NaCl})$ and silver nitrate $(\mathrm{AgNO} 3)$; ACS reagents $\geq 99.0 \%$, were obtained from Sigma Aldrich. Chloroform ( $\geq 99 \%$, Sigma Aldrich), n-hexane (95\%, Sigma Aldrich) and cyclohexane (99.5\%, Sigma Aldrich) were used to make organic solvent/water mixtures. All chemicals were used as received without further purification.

\subsection{Preparation of super-hydrophobic copper and stainless steel mesh}

Super-hydrophobic copper meshes and super-hydrophobic stainless steel meshes were prepared. Copper meshes were washed with $0.5 \% \mathrm{HNO}_{3}(70 \%$, J.T.Baker) and deionised water. The meshes were shaken in $0.02 \mathrm{M} \mathrm{AgNO}_{3}\left(70 \mathrm{~cm}^{3}\right.$, AnalaR, BDH Chemicals Ltd.) for several min. The meshes were rinsed with deionised water and dried at $70^{\circ} \mathrm{C}$. The meshes were then immersed in $100 \mathrm{~cm} 3$ of a $0.1 \mathrm{M}$ 1-decanethiol (96\%, Alfa Aesar) solution (DT) in ethanol (Absolute ACS grade, J.T.Baker). The mixture was shaken intermittently and left overnight. The obtained meshes were rinsed with absolute ethanol and dried at $70^{\circ} \mathrm{C}$ [17]. Other surface modifiers used in this experiment were 0.02 M 10-heptadecafluoro-1- decanethiol (HDFT) (96\%, Sigma-Aldrich) solution in ethanol (Absolute ACS grade, J.T.Baker) and 0.1 M 11- 
mercaptoundecanoic acid, $\mathrm{HS}\left(\mathrm{CH}_{2}\right)_{10} \mathrm{COOH},(95 \%$, Sigma-Aldrich) solution in ethanol to

99 achieve different surface properties. Super-hydrophobic stainless steel meshes could not be

100 coated directly since silver could not be deposited on stainless steel materials. Stainless steel

101 meshes must be copper plated first and then coated with silver and modified following the

102 method above. The anode and cathode in this electro-deposition cell were both connected to a

103 rectifier, which was an external supply of direct current. The anode was connected to a copper

104 plate (the positive terminal), and the cathode was connected to the stainless steel mesh that

105 needed to be coated (the negative terminal). 1.5-5 V were applied across the cell. The copper-

106 plating bath was a copper sulfate solution $(1.0 \mathrm{~mol} / \mathrm{L})$ with some sulfuric acid (a few drops).

107 2.3.Tests and characterization

108 2.3.1. Contact angle measurement

109 The contact angles on the prepared super-hydrophobic copper mesh surfaces with water

110 droplets were monitored using a FTA1000B goniometer instrument (First Ten Angstroms, Ltd).

111 For each sample, five different readings were recorded and the contact angle values were

112 averages of the five measurements made on different points of the sample surface. The FTA

113 1000B goniometer was composed with a drop dispenser with a syringe and needle, a camera,

114 a stage-sample holder and a backlight. It used proprietary FTA32 software to control the height

115 of the drop dispenser and the volume of the water drop and thus determine the contact angle.

116 2.3.2. Pressure Resistance Test

117 A simple and efficient homemade device was designed to test the pressure resistant 118 performance of SH copper mesh (Scheme 1). 


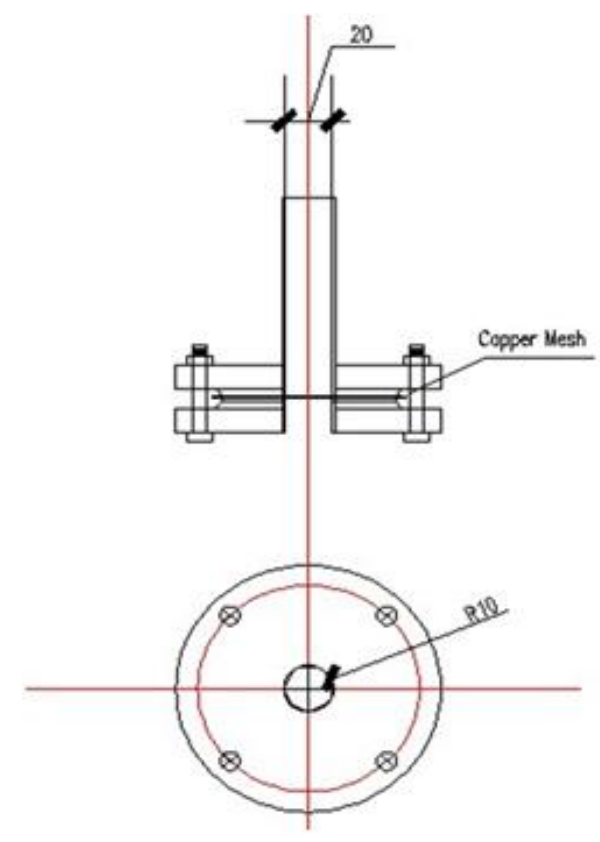

120 Scheme 1: Device for pressure resistance test.

121 The SH copper mesh was held between two iron plates, both of which had a hole of $20 \mathrm{~mm}$

122 diameter in the middle. An iron tube was welded to one of the iron plates and a plastic tube

123 with a length of $100 \mathrm{~cm}$ was connected with this tube. In order to prevent water leakage from

124 the side of the mesh, asbestos washers with holes of $20 \mathrm{~mm}$ diameter in the middle were put

125 between the iron plates as well. The tested mesh was put between the asbestos. The two iron

126 plates were fixed using four bolts tightly. During the test, water was added though the plastic

127 tube into the hole to touch the mesh until the mesh could not resist the high water pressure and

128 water started to leak through mesh pores. The height of water was recorded and the pressure

129 could be calculated. The advantage of this device that it could measure the pressure resistance

130 of mesh accurately without any deformation of mesh surface and without removing the SH

131 coating.

\section{2.3.3. Surface observation}

133 A digital microscope was used to measure the pore size and wire diameter of SH copper mesh. 
134 The topographical microstructure and morphology of the super-hydrophobic copper meshes

135 before and after coating were studied by scanning electron microscopy (Quanta 250 FEG, FEI).

\section{2.3.4. Organic solvent/water separation}

$13710 \mathrm{~g}$ deionized water was mixed with $10 \mathrm{~g}$ organic solvent (chloroform, n-Hexane and

138 cyclohexane separately). A $20 \mathrm{~g}$ mixture of organic solvent and water was used to be separated.

139 The densities of pure water, chloroform, $n$-hexane and cyclohexane were recorded in advance.

140 After separation, the densities of the liquid in two beakers were measured and the percentage

141 of organic solvent and water in each beaker can be calculated. Further to qualitatively measure

142 the separation efficiency, a mixture of $20 \mathrm{~mL}$ of the organic solvent and $30 \mathrm{~mL}$ of $0.1 \mathrm{M} \mathrm{NaCl}$

143 aqueous solution was poured slowly onto the SH copper mesh held over a beaker containing

$14420 \mathrm{~mL}$ of $0.1 \mathrm{M} \mathrm{AgNO}_{3}$ aqueous solution [1].

\section{RESULTS AND DISCUSSION}

$148 \quad 3.1$. Wettability of super-hydrophobic meshes

149 Contact angles were measured to study the hydrophobic properties of the coated SH copper

150 mesh and SH stainless steel mesh surfaces. The contact angles were measured with a $10 \mu \mathrm{L}$

151 water droplet at ambient temperature $(n=5)$. Normally contact angles are measured on planar

152 substrates but in this case the droplets were sufficiently large compared to the dimensions of

153 the mesh that the meshes could be treated as being effectively planar for these purposes, as

154 shown in Figure 1. 

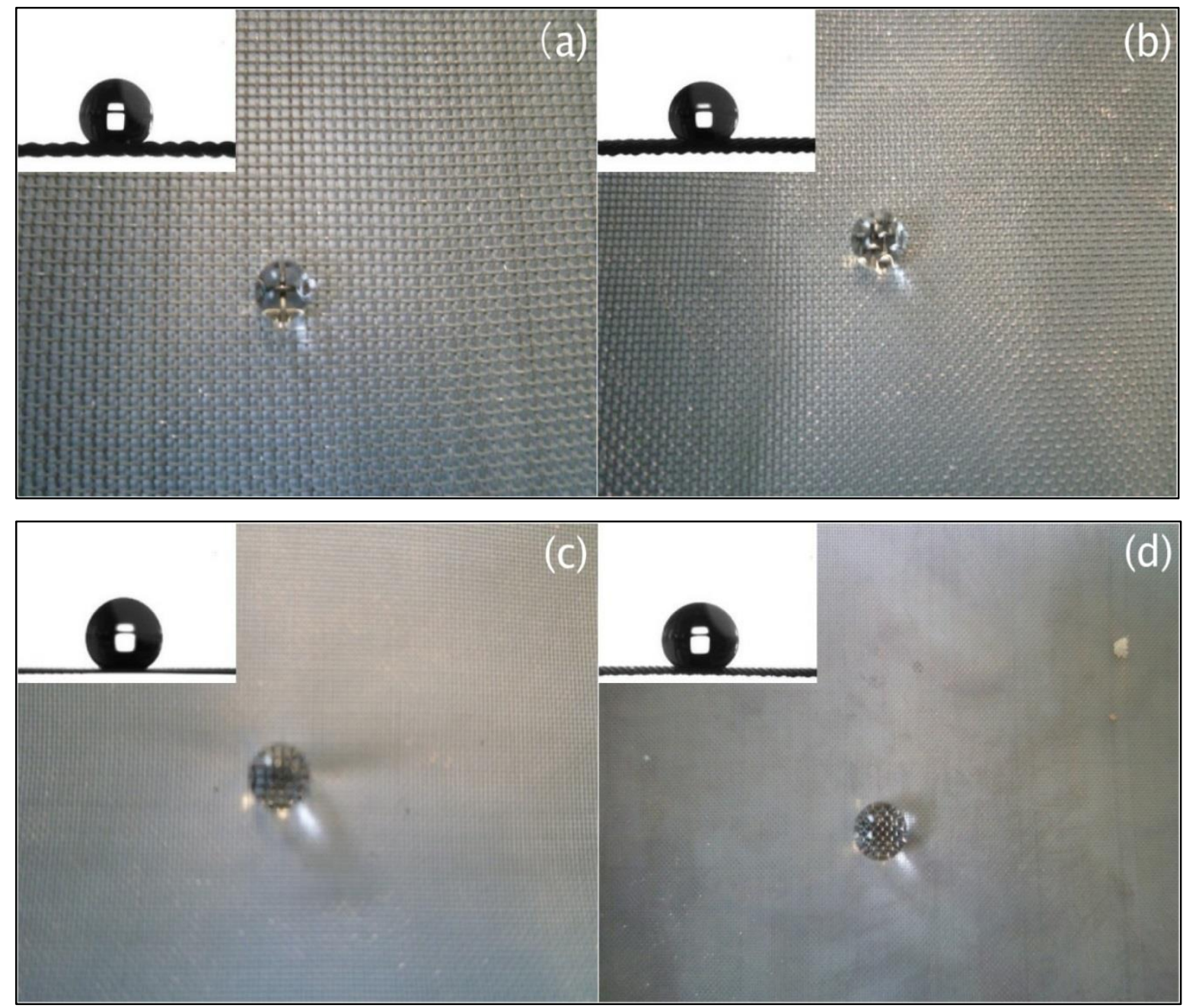

Figure 1: Tilt-view photographs and optical images of water droplets on the HDFT modified

158 copper mesh surface: (a) \#50 copper mesh; (b) \#60 copper mesh; (c) \#100 copper mesh; (d)

$159 \quad \# 120$ copper mesh.

160 It can be seen from Table 1, which brings together the data for the SH copper mesh and SH

161 stainless steel mesh with the same pore size, that both metals have almost the same contact

162 angle and showed the same hydrophobicity for equal mesh sizes. This suggests that adding the

163 electro-deposition process does not change the wettability of the coated mesh [18].

164 Table 1: Contact angle of SH copper meshes with four different sizes.

\begin{tabular}{lcccc}
\hline Samples & \multicolumn{5}{c}{ Contact angle $\left(^{\circ}\right)$} \\
\hline & $\# 50$ & $\# 60$ & $\# 100$ & $\# 120$ \\
\hline
\end{tabular}




\begin{tabular}{ccccc}
\hline SH copper mesh & 137.21 & 138.82 & 140.96 & 141.64 \\
SH stainless steel mesh & 137.32 & 139.21 & 140.38 & 142.55 \\
\hline
\end{tabular}

165 At the same time, meshes with smaller pore size have higher contact angles. The connection

166 between pore sizes of SH meshes and the apparent contact angle has been analyzed

167 mathematically. [2] According to the reformed macroscopic Cassie-Baxter model, the apparent

168 contact angle of SH copper mesh can be given as [2]:

$169 \cos \theta_{r}^{C B}=\frac{b+R\left(\pi-\theta_{e}\right)}{b+R+0.5 d} \cos \theta_{e}+\frac{b+R \sin \left(\pi-\theta_{e}\right)}{b+R+0.5 d}-1$

170 where $\theta_{e}$ is the equilibrium contact angle on a smooth surface, and parameters $b, R$ and $d$ are

171 defined in Figure 2.
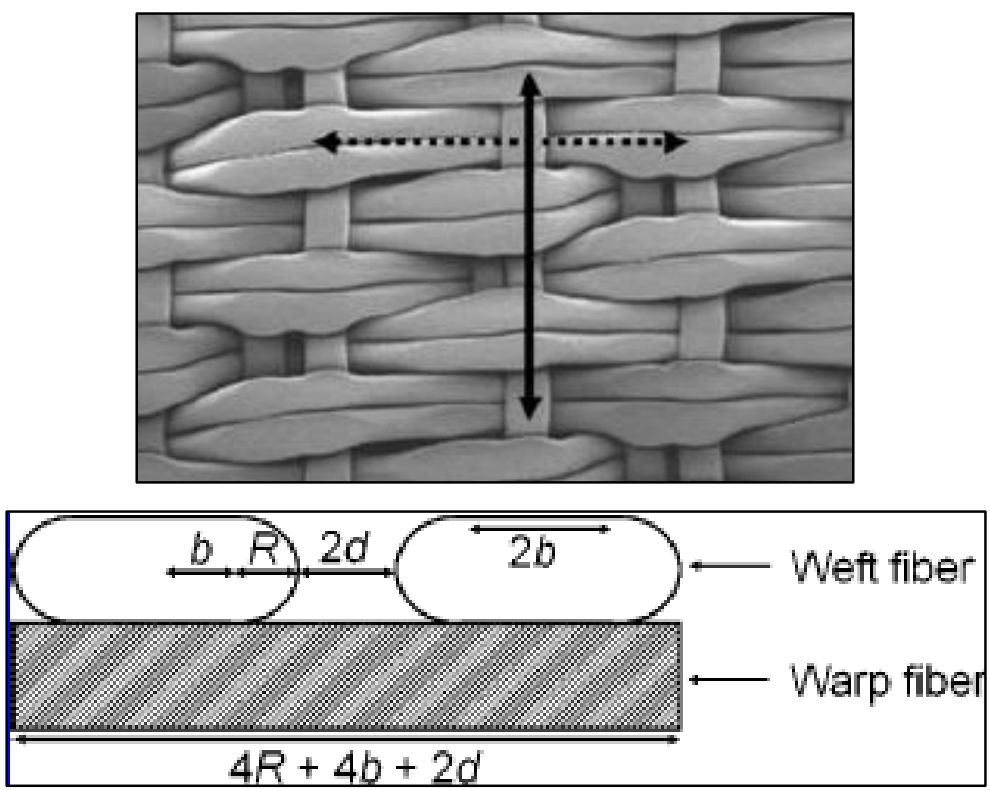

174 Figure 2: Cross-section view of a calendared woven fabric when it is cut in the warp direction.

175 The contact angle of smooth copper film surface $\theta_{e}$ was measured to be $51.0^{\circ}$ and the contact 176 angle of smooth stainless steel film surface was measured to be $51.1^{\circ}$. The parameters of $\mathrm{R}$ and

$177 \mathrm{~d}$ were determined and are presented in Table 2 and Table 3. Since the mesh wires are 
178 columned, the parameter $b$ is equal to 0 . The total area of solid-liquid interface $f_{1}$ and the total

179 area of liquid-air interface $f_{2}$ were calculated using Eqs. (2) and (3) [19]:

$180 \quad f_{1}=r_{f} f=\frac{4 b+4 R \alpha}{4 b+4 R+2 d}$

$181 f_{2}=1-f=1-\frac{4 b+4 R \sin \alpha}{4 b+4 R+2 d}$

182

183 Table 2: Sizes of copper meshes.

\begin{tabular}{lcccc}
\hline & $\begin{array}{c}\text { Mesh count } \\
(\text { per linear inch) }\end{array}$ & $\begin{array}{c}\text { Wire diameter } \\
(\mathbf{m m})\end{array}$ & $\begin{array}{c}\text { Aperture } \\
(\mathbf{m m})\end{array}$ & Open area \\
\hline \#50 & 50 wires or holes & 0.16 & 0.348 & $47 \%$ \\
$\#$ 60 & 60 wires or holes & 0.16 & 0.263 & $39 \%$ \\
$\# 100$ & 100 wires or & 0.03 & 0.224 & $78 \%$ \\
\#120 & holes & & & \\
& 120 wires or & 0.09 & 0.122 & $33 \%$ \\
& holes & & & \\
\hline
\end{tabular}

184 Table 3: Sizes of stainless steel meshes.

\begin{tabular}{ccccc}
\hline & $\begin{array}{c}\text { Mesh count } \\
\text { (per linear inch) }\end{array}$ & $\begin{array}{c}\text { Wire diameter } \\
(\mathbf{m m})\end{array}$ & $\begin{array}{c}\text { Aperture } \\
(\mathbf{m m})\end{array}$ & Open area \\
\hline \#50 & 50 wires or holes & 0.20 & 0.308 & $36.8 \%$ \\
\#60 & 60 wires or holes & 0.16 & 0.263 & $38.7 \%$ \\
\#70 & 70 wires or holes & 0.16 & 0.203 & $31.3 \%$ \\
$\# \mathbf{1 0 0}$ & 100 wires or holes & 0.112 & 0.142 & $31.3 \%$ \\
$\# \mathbf{1 0 0 A}$ & 100 wires or holes & 0.056 & 0.142 & - \\
$\# \mathbf{1 2 0}$ & 120 wires or holes & 0.09 & 0.122 & $33.0 \%$ \\
$\# \mathbf{2 5 0}$ & 250 wires or holes & 0.04 & 0.062 & $37.0 \%$ \\
\hline
\end{tabular}

185 The predicted results of contact angles of SH copper meshes and SH stainless steel meshes are 

shown in Tables 4 and 5. Clearly, $f_{1}+f_{2}>1$ on these rough surfaces, which means that the SH meshes were at Cassie-Baxter state [20].

188 Table 4: Comparison of predicted and measured contact angles of SH copper meshes.

\begin{tabular}{ccccc}
\hline Samples & $\mathbf{\# 5 0}$ & $\mathbf{\# 6 0}$ & $\mathbf{\# 1 0 0}$ & $\mathbf{\# 1 2 0}$ \\
\hline$f_{1}$ & 0.709 & 0.851 & 0.266 & 0.955 \\
$f_{2}$ & 0.789 & 0.747 & 0.921 & 0.716 \\
Contact angle measured (Deg) & 137.2 & 138.8 & 141.0 & 141.6 \\
Contact angle predicted (Deg) & 139.8 & 134.8 & 157.0 & 131.2 \\
\hline
\end{tabular}

189

190 Table 5: Comparison of predicted and measured contact angles of SH stainless steel meshes.

\begin{tabular}{ccccc}
\hline $\begin{array}{c}\text { Mesh size } \\
(\boldsymbol{\mu m})\end{array}$ & $\boldsymbol{f}_{\mathbf{1}}$ & $\boldsymbol{f}_{\mathbf{2}}$ & $\begin{array}{c}\text { Contact angle } \\
\text { measured } \\
(\mathbf{D e g})\end{array}$ & $\begin{array}{c}\text { Contact angle } \\
\text { predicted } \\
(\mathbf{D e g})\end{array}$ \\
\hline \#50 & 0.885 & 0.708 & 137.3 & 138.7 \\
\#60 & 0.851 & 0.720 & 139.2 & 139.7 \\
$\# \mathbf{7 0}$ & 0.991 & 0.673 & 140.3 & 135.5 \\
$\# \mathbf{1 0 0}$ & 0.992 & 0.673 & 140.4 & 135.4 \\
$\# \mathbf{1 0 0 A}$ & 0.636 & 0.790 & 143.6 & 146.4 \\
$\# \mathbf{1 2 0}$ & 0.955 & 0.685 & 142.6 & 136.6 \\
$\# \mathbf{2 5 0}$ & 0.882 & 0.709 & 149.9 & 138.8 \\
\hline
\end{tabular}

191 The predicted values of apparent contact angles of SH meshes are close to the experimental

192 values of apparent contact angles, however, the equilibrium contact angle on a smooth surface

193 plays an important role in the predicted values and a difference of even $0.1^{\circ}$ may cause an

194 important error in this final apparent contact angle of around $10^{\circ}$. Thus, the predicted values

195 may be different from the experimental values. This method was first used to predict the

196 apparent contact angle of HDFT modified SH copper mesh and SH stainless steel mesh. The

197 predicted values of contact angle are not only associated with the pore size of mesh, but also 
connected with the diameter of wire [21]. The SH meshes with smaller pore size and thinner

199 wire have higher contact angles according to Tables 4 and 5. As can be seen in Table 6, the

200 only difference between SH mesh \#100 and SH mesh \#100A is the wire diameter.

201 Table 6: The effect of wire diameter on contact angle of SH stainless steel meshes.

\begin{tabular}{ccccc}
\hline Sample & Pore size $(\boldsymbol{\mu m})$ & $\begin{array}{c}\text { Wire diameter } \\
(\boldsymbol{\mu m})\end{array}$ & $\begin{array}{c}\text { Contact angle } \\
\text { measured (Deg) }\end{array}$ & $\begin{array}{c}\text { Contact angle } \\
\text { predicted }(\mathbf{D e g})\end{array}$ \\
\hline$\# \mathbf{1 0 0}$ & 142 & 112 & 140.4 & 135.4 \\
$\# 100 A$ & 142 & 56 & 143.6 & 146.4 \\
\hline
\end{tabular}

202 The diameter of \#100A is only half of that of \#100. The measured contact angle of \#100A is

$2033.36^{\circ}$ higher than that of \#100 and the predicted contact angle of $\# 100 \mathrm{~A}$ is $10.93^{\circ}$ higher than

204 that of \#100.

205 Morphology of the surface

206 The morphology microstructures of the copper meshes before and after coating were observed

207 by scanning electron microscopy. The SEM images of these meshes are shown in Figure 3.

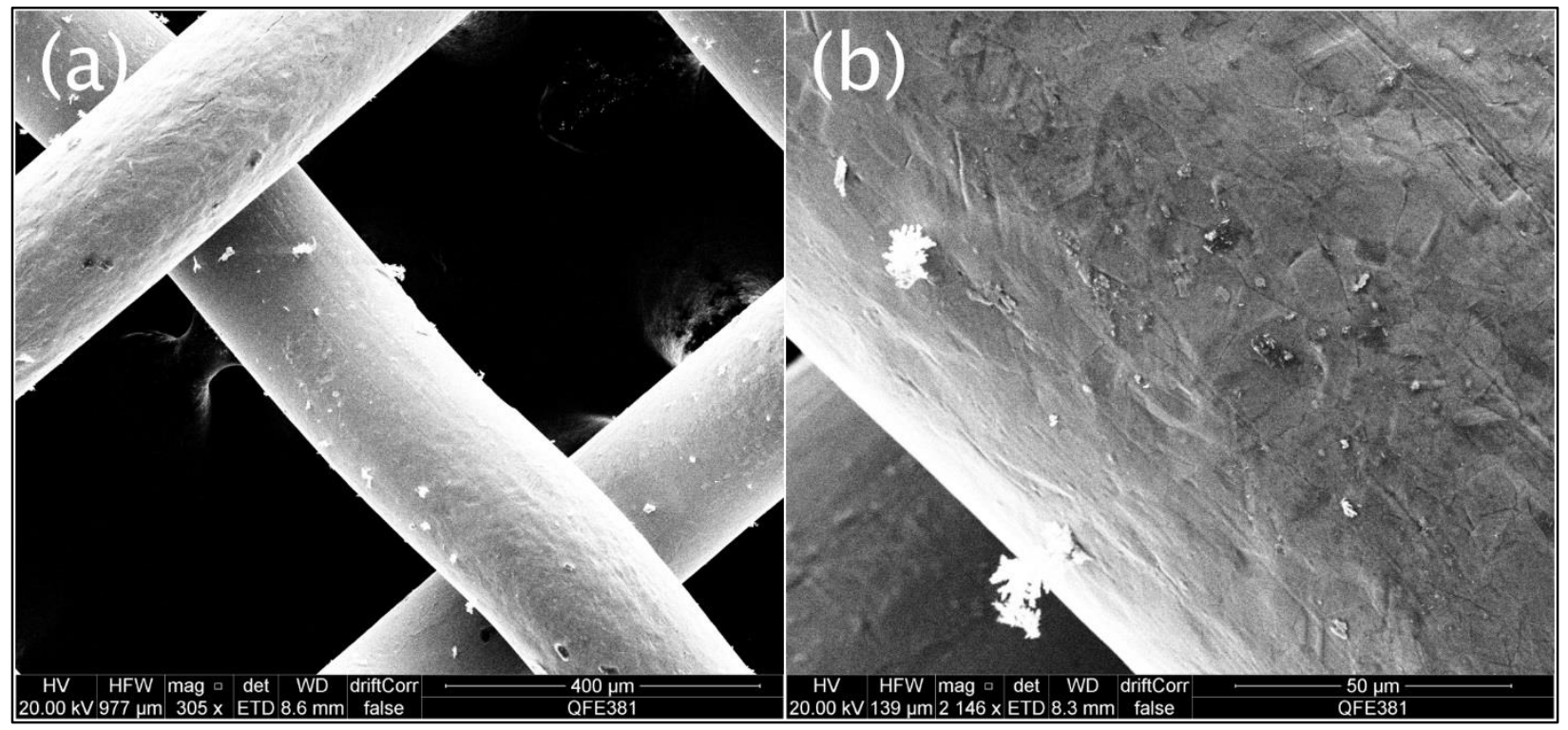



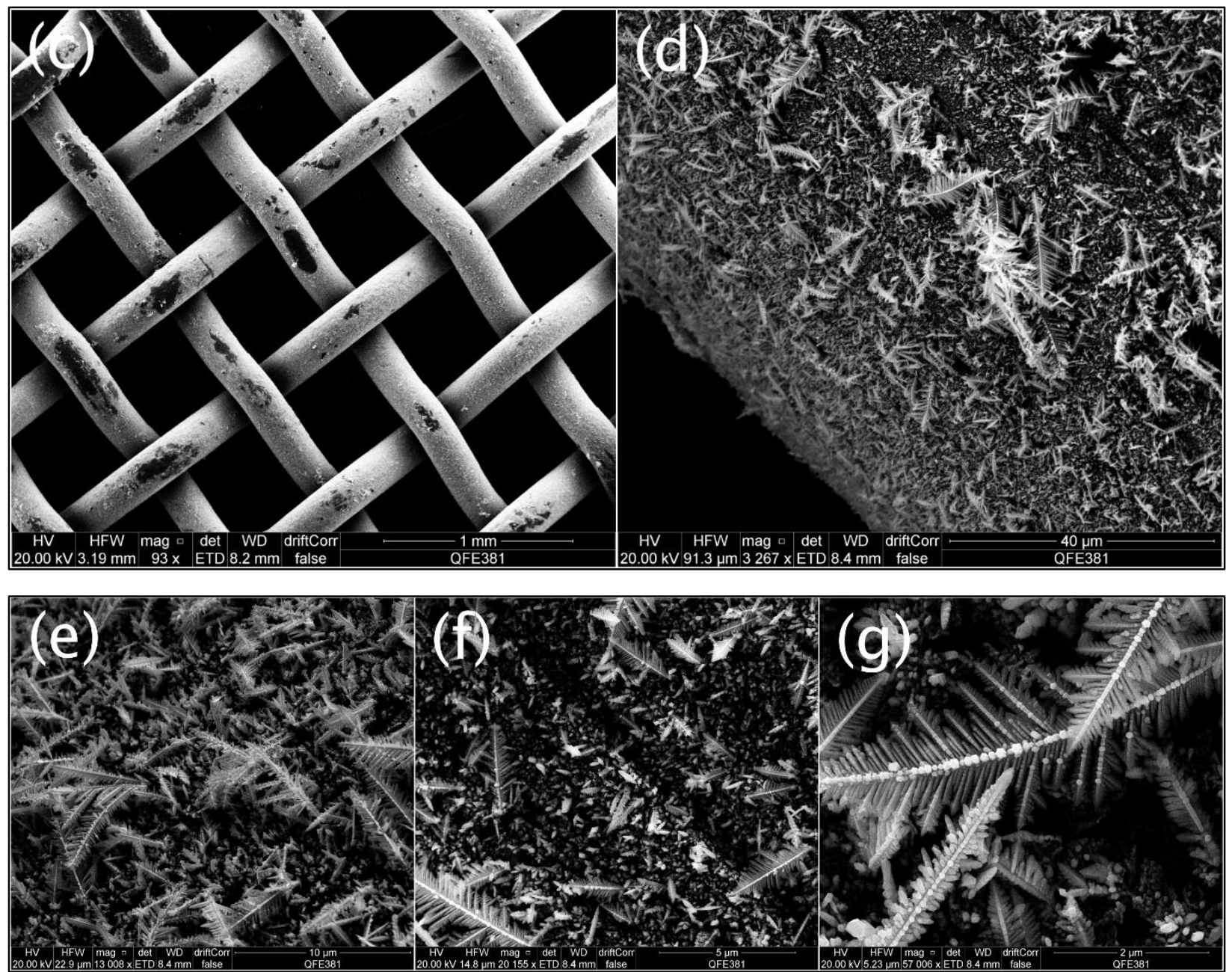

211 Figure 3: SEM micrographs of copper mesh: (a) (b) uncoated mesh; (c) (d) coated mesh; (e)

212 (f) (g) silver on copper film.

213 The SEM images indicate that the original copper mesh has a smooth surface with pores of

214 rectangular shape and the mesh wires crisscross together, while the silver forms a thin film in

215 the therstitial opening of the mesh and forms a rough surface with plenty of "leaves" growing

216 on the surface. These "leaves" grow much leafier if the mesh was immersed in silver solution

217 longer, i.e. around $15 \mathrm{~min}$. The "leaves" have a length of around 2-5 $\mu \mathrm{m}$ and they cover all

218 over the mesh wires. Compared with the mesh width of $160 \mu \mathrm{m}$, the coated mesh become

219 thicker by around 4-6 $\mu \mathrm{m}$ in width after coated, which can be ignored compared with the width

220 of copper pores. The stainless steel mesh needs to be deposited with copper first before coating. 
221 Figure 4 shows an optical image of the \#250 stainless steel mesh with a pore size of $122 \mu \mathrm{m}$.

222 It has a shiny, smooth metallic surface.

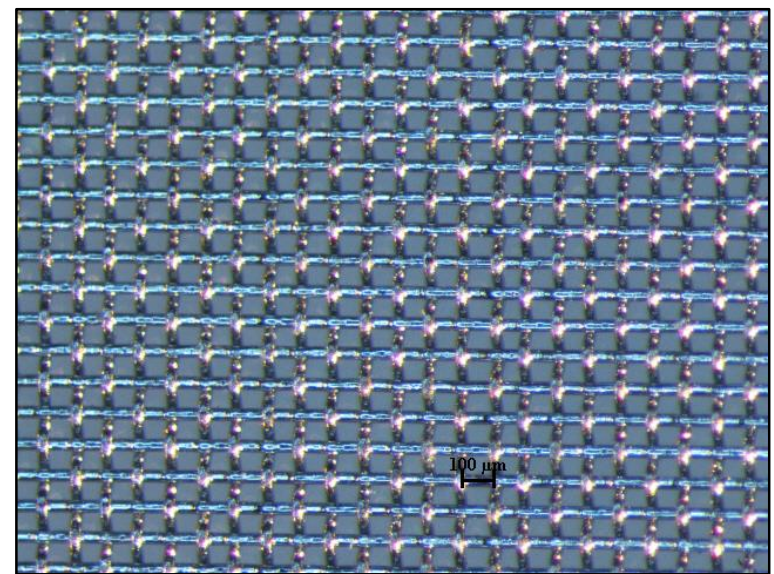

224 Figure 4: Uncoated \#250 Stainless steel mesh.

225 Figure 5 shows stainless steel mesh deposited with copper by electro-deposition and a 226 copper/silver coated SH stainless steel mesh modified with HDFT.

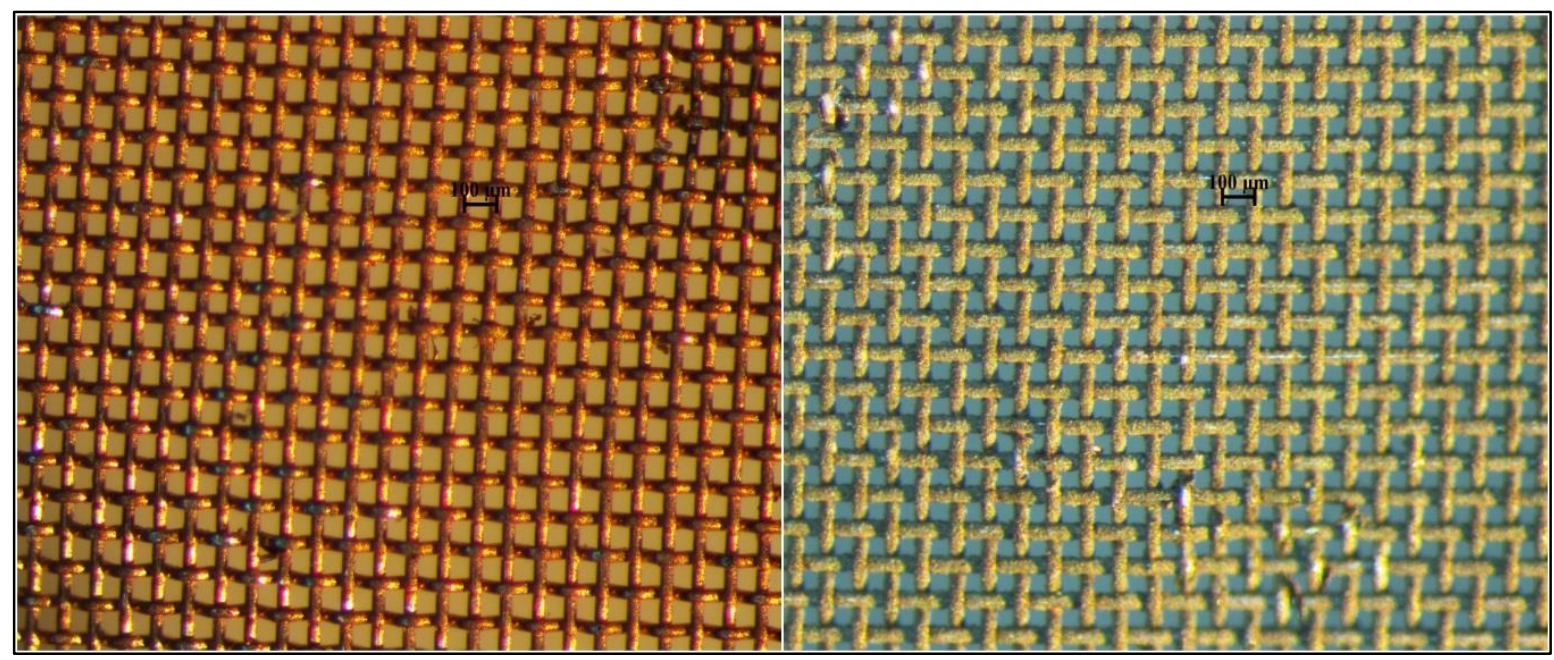

228 Figure 5: \#250 Stainless steel mesh electro-deposited with copper (left); \#250 SH stainless

229 steel mesh deposited with copper and silver and modified with HDFT (right).

230 These microscopy images indicate that copper can be evenly deposited on stainless steel

231 surfaces simply through electro-deposition method even on the cross-section part, while the 
232 color turns to be dark yellow after being coated. However, the pores would not be blocked after 233 treatment.

234 3.2. Pressure resistance evaluation

235 Pressure resistance property is another important characteristic of hydrophobic porous surface.

236 The height of the water column was recorded and the pressure resistance of the mesh could be

237 calculated as:

$238 \quad \mathrm{P}=\rho \mathrm{gh}$

239 where $\rho$ is the water density, $g$ is the gravitational constant and $\mathrm{h}$ is the water height. It can be 240 seen from Table 7 that with a decrease of pore size of SH stainless steel mesh, the pressure

241 resistance of SH mesh increases and for \#250 SH stainless steel mesh with a pore size of 122 $242 \mu \mathrm{m}$, the pressure as high as $4900 \mathrm{~Pa}$ can be achieved, which is $50 \mathrm{~cm}$ water height.

244 Table 7: Experimental value of pressure resistance of SH copper mesh.

\begin{tabular}{cccccc}
\hline Sample & $\mathbf{\# 5 0}$ & $\mathbf{\# 6 0}$ & $\mathbf{\# 1 0 0}$ & $\mathbf{\# 1 2 0}$ & $\mathbf{\# 2 5 0}$ \\
\hline Water height $(\mathrm{mm})$ & 37.6 & 41.0 & 92 & 220 & 500 \\
Pressure resistance $(\mathrm{Pa})$ & 368.5 & 401.8 & 901.6 & 2156 & 4900 \\
\hline
\end{tabular}

245 At the same time, the copper mesh can be considered as a combination of capillaries [22]. The

246 water level that the $\mathrm{SH}$ mesh can resist can be calculated as:

$247 \quad H=-\frac{2 \gamma \cos \theta^{C B}}{\rho g R}$

248 where $\gamma$ is the surface tension of water, $\theta$ is the contact angle of SH copper mesh, and $R$ is the

249 radius of the holes in the mesh wire. The surface tension of water is $71.4 \mathrm{mN} / \mathrm{m}$. The predicted 250 heights of water that the SH meshes can resist are shown in Table 8. 
251 Table 8: Predicted value of pressure resistance of SH copper meshes.

\begin{tabular}{cccccc}
\hline Sample & $\mathbf{\# 5 0}$ & $\mathbf{\# 6 0}$ & $\mathbf{\# 1 0 0}$ & $\mathbf{\# 1 2 0}$ & $\mathbf{\# 2 5 0}$ \\
\hline $\begin{array}{c}\text { Predicted Height }(\mathrm{mm}) \\
\text { Predicted Pressure }\end{array}$ & 89.42 & 101.5 & 142.4 & 123.8 & 437.6 \\
resistance $(\mathrm{Pa})$ & 876.3 & 994.4 & 1395.6 & 1213.7 & 4288.8 \\
\hline
\end{tabular}

252

253 Compared with Table 7, the predicted values in Table 8 are much closer to the measured value

254 when the pore size of mesh is small. With high-pressure resistance of $4900 \mathrm{~Pa}$ and tough surface

255 structure, \#250 SH stainless steel mesh can be produced as microphones and earphones with

256 strong waterproof property for special uses, such as by firefighters, police officers and divers.

257 3.3. $\mathrm{pH}$ - controllable water permeation

258 It has been determined that the SH copper mesh has a controllable water permeation property

259 by adjusting the $\mathrm{pH}$ of water solution. For acidic water solutions or neutral water, the SH copper

260 mesh is super-hydrophobic, and the water cannot permeate the film because of the large

261 negative capillary effect resulting from the nanostructures. However, for basic solutions with a

$262 \mathrm{pH}$ value higher than 8 , the film shows super-hydrophilic property, and the solution can

263 permeate the film and keep dropping down as is shown in Figure 6. 


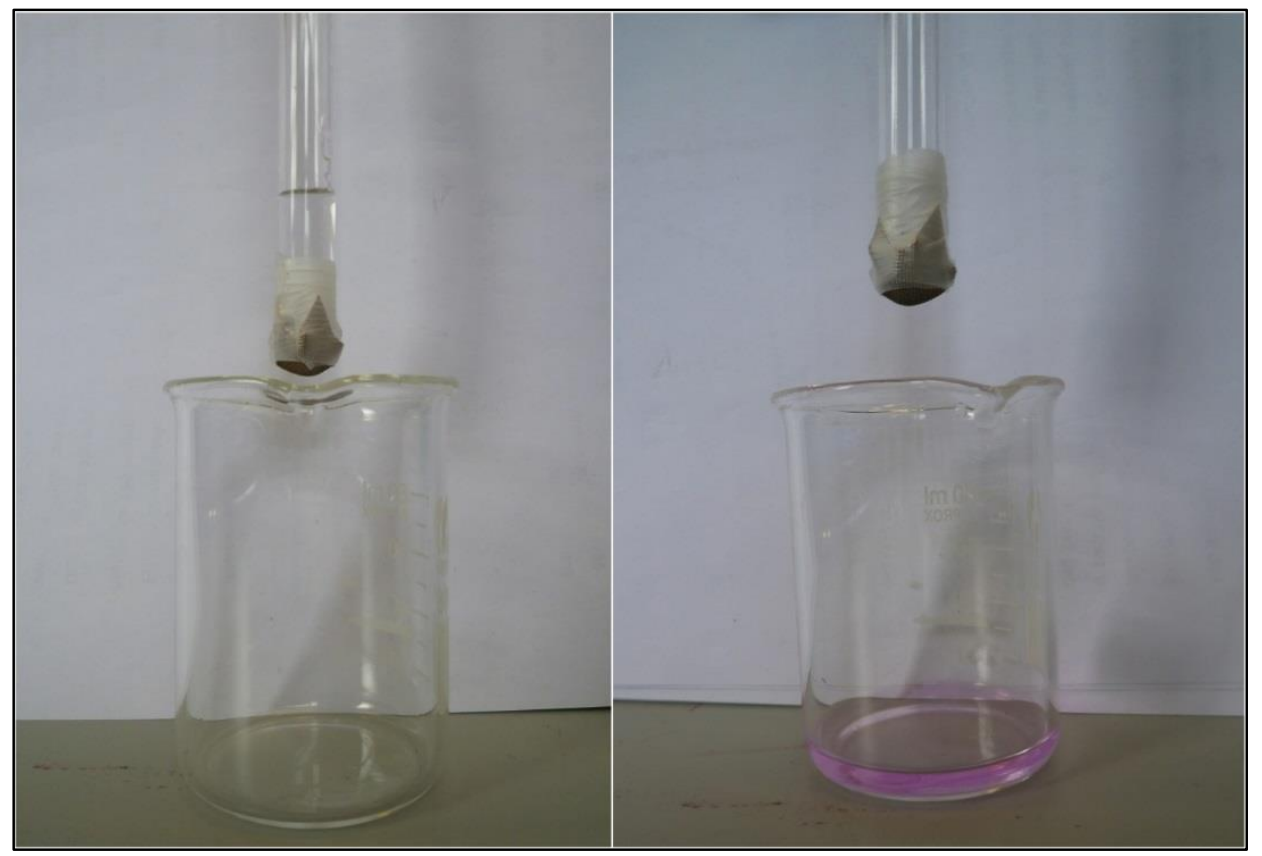

265 Figure 6: The $\mathrm{pH}$-controllable water permeation device. Neutral water cannot penetrate the

266 rough mesh film (left). Basic water can penetrate the rough mesh film (right). Phenolphthalein

267 was used as $\mathrm{pH}$ indicator.

268 The SH copper mesh was modified with $0.1 \mathrm{M} \mathrm{HS}\left(\mathrm{CH}_{2}\right)_{10} \mathrm{COOH}$ solution in ethanol. It was

269 known that basic solution would react with $-\mathrm{COOH}$ structure and led to the de-protonation of

270 thiol chain, while neutral water did not cause any impact on thiol chain. The contact angle of

271 neutral water on SH copper mesh (\#100) is higher than $140.96^{\circ}$, while the contact angle of

272 basic water $(\mathrm{pH}=14)$ on $\mathrm{SH}$ copper mesh $(\# 100)$ is as low as $10.24^{\circ}$. By changing the $\mathrm{pH}$ of

273 water solution, the controllable permeation of SH copper mesh can be realized simply.

274 3.4. Separating water and organic solvents

275 The SH copper mesh used in this study was modified with HDFT. Interestingly, as shown in

276 Figure 7, when a water droplet is laid on SH copper mesh, the mesh shows high super-

277 hydrophobicity and water droplet rolls as a water ball. 

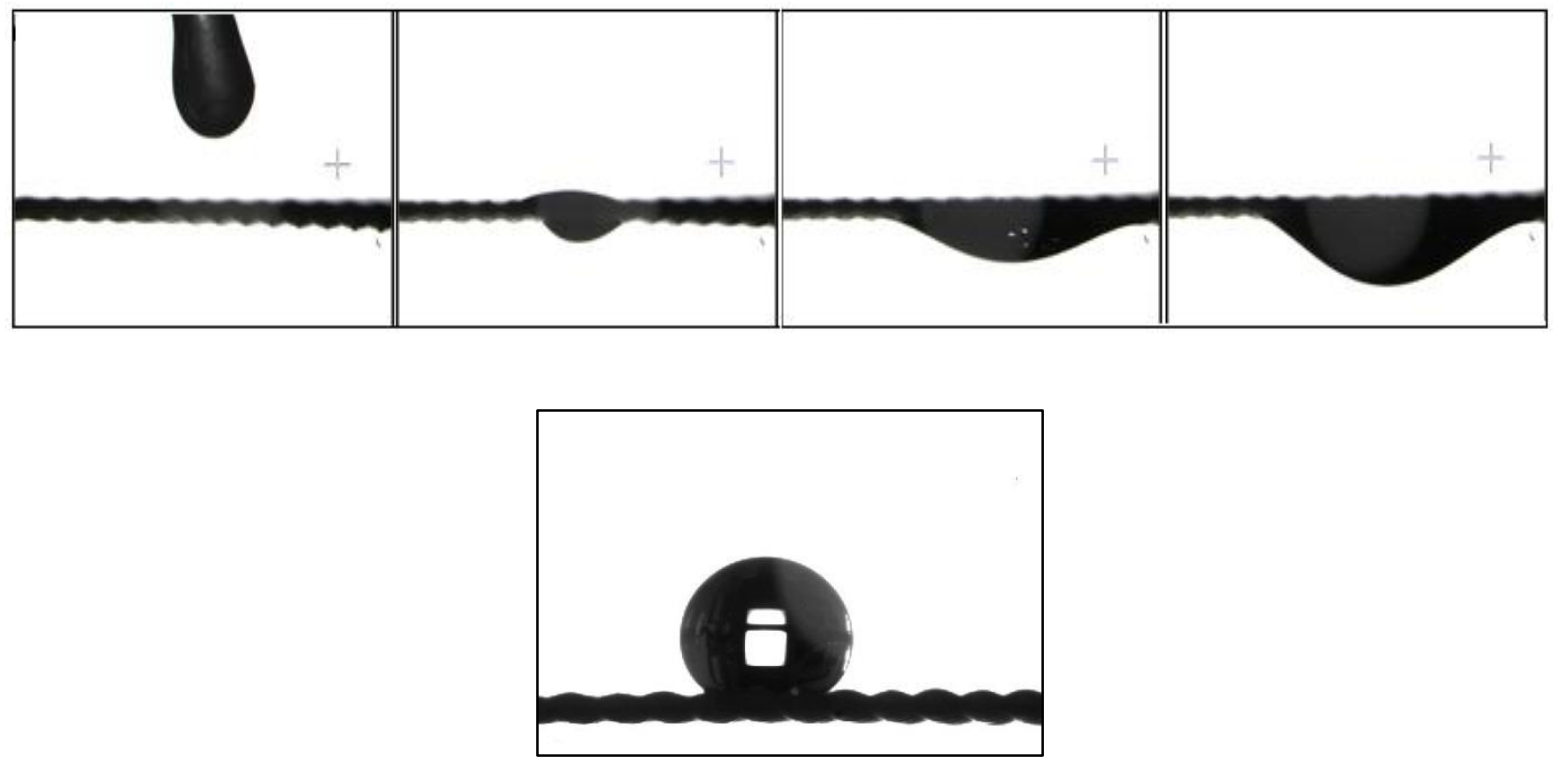

280 Figure 7: Organic solvent droplet (Chloroform) on \#100 SH copper mesh (top); Water droplet on \#100 SH copper mesh (bottom).

282 While organic solvents like chloroform permeate through the mesh freely and drop down easily. The SH copper mesh showed strong super-oleophilicity in this process. The contact angle for chloroform on SH copper mesh (\#100) is only $0^{\circ}$. This phenomenon indicates that the SH copper mesh can behave differently for different materials and it can be made an effective tool for organic solvents/water separation. A homemade device was used to separate the mixture of organic solvents and water. A slightly tilted SH copper mesh was placed above two beakers. The mixture of organic solvent and water was dropped through a burette on the mesh at a rate of one droplet per second. During this process, organic solvent droplets would permeate though mesh and fall into the beaker beneath it, while water droplets would roll along

291 the mesh and drop into another beaker. Thus, the mixture (10 g deionized water was mixed with $10 \mathrm{~g}$ organic solvent (chloroform, n-Hexane and cyclohexane separately)) was separated.

293 The separation efficiency in Table 9 is the percentage of water that can be recycled from the 294 mixture.

295 Table 9: Separation efficiency for different organic solvent/water mixtures. 


\begin{tabular}{cccc}
\hline Mesh size & \multicolumn{3}{c}{ Efficiency } \\
\hline & Chloroform & n-Hexane & Cyclohexane \\
\cline { 2 - 4 } \#50 copper mesh & $99.7 \%$ & $99.8 \%$ & $99.9 \%$ \\
\#60 copper mesh & $94.8 \%$ & $99.0 \%$ & $98.5 \%$ \\
\#100 copper mesh & $94.1 \%$ & $98.8 \%$ & $93.8 \%$ \\
\#120 copper mesh & $91.6 \%$ & $97.7 \%$ & $92.0 \%$ \\
\hline
\end{tabular}

296 It can be seen in Table 9 that an efficiency of as high as $99.9 \%$ can be achieved using SH \#50

297 copper mesh for cyclohexane and water mixture. While for all the mixtures, a decreasing of the

298 pore size of SH copper mesh causes the decreasing of separation efficiency.

299 A more sensitive method of detecting water ingress was to set up an experiment such that water

300 penetration would cause a visible precipitate of $\mathrm{AgCl}$. It was experimentally determined that a

301 white precipitate of $\mathrm{AgCl}$ could be seen in a $20 \mathrm{~mL}$ aqueous solution of $0.1 \mathrm{M} \mathrm{AgNO}_{3}$ if as little

302 as $50 \mu \mathrm{L}$ of $0.005 \mathrm{M} \mathrm{NaCl}$ was added. Experiments were then carried out with the \#50 copper

303 mesh using a mixture of the organic solvent and aqueous $0.1 \mathrm{M} \mathrm{NaCl}$ solution. After the

304 separation, the $\mathrm{AgNO}_{3}$ aqueous solution stayed clear, confirming the extremely high organic

305 solvent/water separation efficiency which can be calculated as $\leq 0.01 \%$ of the aqueous layer

306 penetrating the film. No decrease in performance was observed after ten cycles of organic

307 solvent/water separation for all mesh sizes (using both density calculations and the $308 \quad \mathrm{AgNO}_{3} / \mathrm{NaCl}$ test).

309 However, SH copper mesh can only separate organic solvents that are not miscible with water.

310 For organic solvents that are miscible with water e.g. ethanol solution, the effect of adding

311 solvent is to decrease the surface tension of the liquid (Table 10). This in turn will reduce the

312 contact angles and also lead ultimately to the liquid penetrating the mesh. The contact angles

313 of the mixtures of ethanol and water with ethanol concentrations from $0 \%$ to $100 \%$ were 
314 measured (Table 10). Also shown are the compositions where the liquid penetrated the mesh.

315 Table 10: Contact angle of mixtures of ethanol and water with ethanol concentrations from $3160 \%$ to $100 \%$.

\begin{tabular}{cccccc}
\hline Concentration \% & Surface tension [23] & \multicolumn{4}{c}{ Contact angle (Deg) } \\
\cline { 3 - 6 } & (mN/m) at 298K & $\mathbf{\# 5 0}$ & $\mathbf{\# 6 0}$ & $\# \mathbf{1 0 0}$ & $\# \mathbf{1 2 0}$ \\
\cline { 3 - 6 } 0 & 72.01 & 137.2 & 138.8 & 141.0 & 141.6 \\
10 & 47.53 & 121.7 & 127.2 & 132.8 & 127.9 \\
20 & 37.97 & 117.9 & 126.7 & 131.2 & 126.6 \\
30 & 32.98 & 108.6 & 123.7 & 127.8 & 119.8 \\
40 & 30.16 & 110.7 & 114.2 & 116.8 & 111.2 \\
50 & 27.96 & 106.0 & 112.8 & 111.9 & 107.4 \\
60 & 26.23 & 97.7 & 102.2 & 108.4 & 106.9 \\
70 & 25.01 & 97.1 & 96.2 & 109.3 & 96.5 \\
80 & 23.82 & 0 & 94.4 & 99.7 & 89.4 \\
90 & 22.72 & 0 & 0 & 98.5 & 87.8 \\
100 & 21.82 & 0 & 0 & 0 & 0 \\
\hline
\end{tabular}

317 It is clear that for any given mesh altering the contact angle to values close to or below $90^{\circ}$

318 allows the liquid to penetrate. The composition at which this occurs is different for different

319 meshes, with SH \#100 and SH\#120 copper mesh able to support mixture with lower surface

320 tensions than the SH \#50 and SH\#60 meshes.

\section{CONCLUSIONS}

322 The properties of copper mesh and stainless steel mesh coated with super-hydrophobic material

323 were investigated including contact angle, surface topographic structure, $\mathrm{pH}$-controllable

324 permeation and its application in organic solvents/water separation. A new method to test the

325 pressure resistance of super-hydrophobic mesh was applied in this study to avoid any

326 deformation of mesh and water leakage from the edges. Based on the results obtained the

327 following conclusions can be drawn: 
1. SH copper mesh and SH stainless steel mesh with the same pore size had almost the same contact angle and showed the same hydrophobicity and meshes with smaller pore size have higher contact angles.

2. SH copper mesh with a pore size of $122 \mu \mathrm{m}$ can resist water pressure of $4900 \mathrm{~Pa}$ and a decrease of pore size of mesh can increase the pressure resistance of SH copper mesh. The water level can be mathematically calculated using a capillary combination equation.

3. The $\mathrm{SH}$ copper mesh modified with $0.1 \mathrm{M} \mathrm{HS}\left(\mathrm{CH}_{2}\right)_{10} \mathrm{COOH}$ solution in ethanol has a controllable water permeation property by simply adjusting the $\mathrm{pH}$ of water solution.

4. SH copper mesh shows super-oleophilicity with organic solvents with a contact angle of $0^{\circ}$ and it can be made an effective tool for organic solvents/water separation. The separation efficiency of SH copper mesh to separate the mixture of organic solvent and water can be as high as $99.8 \%$.

\section{REFERENCES}

[1] L. Wu, J. Zhang, B. Li, A. Wang, Mechanical- and oil-durable superhydrophobic polyester materials for selective oil absorption and oil/water separation, Journal of Colloid and Interface Science, 413 (2014) 112-117.

[2] Z.X. Jiang, L. Geng, Y.D. Huang, S.A. Guan, W. Dong, Z.Y. Ma, The model of rough wetting for hydrophobic steel meshes that mimic Asparagus setaceus leaf, Journal of Colloid and Interface Science, 354 (2011) 866-872.

[3] X. Zhu, Z. Zhang, B. Ge, X. Men, X. Zhou, Q. Xue, A versatile approach to produce superhydrophobic materials used for oil-water separation, Journal of Colloid and Interface Science, 432 (2014) 105-108.

[4] T. An, Fabrication of a superhydrophobic water-repellent mesh for underwater sensors, Journal of Sensor Science and Technology, 22 (2013) 100-104.

[5] A.B.D. Cassie, S. Baxter, Wettability of porous surfaces, Transactions of the Faraday Society, 40 (1944) 546-551.

[6] A.M.J. Davis, E. Lauga, The friction of a mesh-like super-hydrophobic surface, Physics of Fluids, 21 (2009) 1-8. 
[7] T. Dalton, D. Jin, Extent and frequency of vessel oil spills in US marine protected areas,

360 Marine Pollution Bulletin, 60 (2010) 1939-1945.

361 [8] Jikang Yuan, Xiaogang Liu, Ozge Akbulut, Junqing Hu, Steven L. Suib, Jing Kong, F.

362 Stellacci, Superwetting nanowire membranes for selective absorption, Nature Nanotechnology,

3633 (2008) $332-336$.

364 [9] D. Zang, F. Liu, M. Zhang, X. Niu, Z. Gao, C. Wang, Superhydrophobic coating on

365 fiberglass cloth for selective removal of oil from water, Chemical Engineering Journal, 262

366 (2015) 210-216.

367 [10] Y. Cao, Z. Zhang, L. Tao, K. Li, Z. Xue, L. Feng, Y. Wei, Mussel-inspired chemistry and

368 Michael addition reaction for efficient oil/water separation, ACS Applied Materials and 369 Interfaces, 5 (2013) 4438-4442.

370 [11] D.-D. La, T.A. Nguyen, S. Lee, J.W. Kim, Y.S. Kim, A stable superhydrophobic and

371 superoleophilic $\mathrm{Cu}$ mesh based on copper hydroxide nanoneedle arrays, Applied Surface

372 Science, 257 (2011) 5705-5710.

373 [12] L. Wu, J. Zhang, B. Li, A. Wang, Magnetically driven super durable superhydrophobic

374 polyester materials for oil/water separation, Polymer Chemistry, 5 (2014) 2382-2390.

375 [13] W. Song, F. Xia, Y. Bai, F. Liu, T. Sun, L. Jiang, Controllable Water Permeation on a

376 Poly(N-isopropylacrylamide)-Modified Nanostructured Copper Mesh Film†, Langmuir, 23

377 (2006) 327-331.

378 [14] M. Callies, D. Quéré, On water repellency, Soft Matter, 1 (2005) 55-61.

379 [15] J. Drelich, E. Chibowski, D.D. Meng, K. Terpilowski, Hydrophilic and superhydrophilic 380 surfaces and materials, Soft Matter, 7 (2011) 9804-9828.

381 [16] A.B. Gurav, Q. Xu, S.S. Latthe, R.S. Vhatkar, S. Liu, H. Yoon, S.S. Yoon, 382 Superhydrophobic coatings prepared from methyl-modified silica particles using simple dip383 coating method, Ceramics International, 41 (2015) 3017-3023.

384 [17] i) I.A. Larmour, G.C. Saunders, S.E.J. Bell, Remarkably Simple Fabrication of 385 Superhydrophobic Surfaces Using Electroless Galvanic Deposition, Angewandte Chemie 386 International Edition, 46 (2007) 1710-1712.

387 ii) I.A. Larmour, G.C. Saunders, S.E.J. Bell, Compressed Metal Powders that Remain 388 Superhydrophobic after Abrasion, ACS Applied Materials \& Interfaces, 2 (2010) 2703-2706.

389 [18] Weifeng Zhang, Yingze Cao, Na Liu, Yuning Chen, L. Feng, A novel solution-controlled 390 hydrogel coated mesh for oil/water separation based on monolayer electrostatic self-assembly, 391 RSC Advances 4 (2014) 51404-51410.

392 [19]A. Marmur, Wetting on Hydrophobic Rough Surfaces: To Be Heterogeneous or Not To 393 Be?, Langmuir, 19 (2003) 8343-8348.

394 [20] A. Siddaramanna, N. Saleema, D.K. Sarkar, A versatile cost-effective and one step process 395 to engineer $\mathrm{ZnO}$ superhydrophobic surfaces on Al substrate, Applied Surface Science, 311 396 (2014) 182-188.

397 [21] Sanjay Subhash Latthe, Annaso Basavraj Gurav, Chavan Shridhar Maruti, R.S. Vhatkar, 398 Recent Progress in Preparation of Superhydrophobic Surfaces: A Review, Journal of Surface 399 Engineered Materials and Advanced Technology, 2 (2012) 76-94.

400 [22] Z.X. Jiang, L. Geng, Y.D. Huang, Design and Fabrication of Hydrophobic Copper Mesh 401 with Striking Loading Capacity and Pressure Resistance, The Journal of Physical Chemistry 402 C, 114 (2010) 9370-9378.

403 [23] G Vhquez, E Alvarez, JM Navaza, Surface Tension of Alcohol + Water from 20 to $50^{\circ} \mathrm{C}$, 404 Journal of Chemical and Engineering Data, 40 (1995), 611-614. 